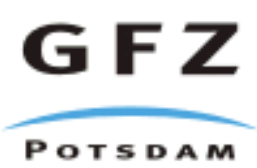

Originally published as:

Heiden, U., Segl, K., Kaufmann, H. (2007): Determination of robust spectral features for identification of urban surface materials in hyperspectral remote sensing data. - Remote Sensing of Environment, 111, 4, 537-552

DOI: 10.1016/j.rse.2007.04.008. 


\title{
Determination of robust spectral features for identification of urban surface materials in hyperspectral remote sensing data
}

\author{
Uta Heiden ${ }^{\mathrm{a}}$ \\ ${ }^{a}$ German Aerospace Center, German Remote Sensing Data Center, Dept. of \\ Environment and Security, Oberpfaffenhofen, D-82234 Wessling, Germany \\ Karl Segl ${ }^{\mathrm{b}}$, Sigrid Roessner ${ }^{\mathrm{b}}$, Hermann Kaufmann ${ }^{\mathrm{b}}$ \\ ${ }^{\mathrm{b}}$ GeoForschungsZentrum Potsdam (GFZ), Dept. of Geodesy and Remote Sensing, \\ Remote Sensing Section, Telegrafenberg, 14473 Potsdam, Germany
}

\begin{abstract}
Hyperspectral remote sensing data open up new opportunities for analyzing urban areas characterized by a large variety of spectrally distinct surface materials. Spectroscopic analysis using diagnostic spectral features yields the potential for automated identification and mapping of these materials. This study proposes a new approach for the determination and evaluation of such spectral features that are robust against spectral overlap between material classes and within class variability. Analysis is based on comprehensive field and image spectral libraries of more than 21.000 spectra of surface materials widely-used in German cities. The robustness of the interactively defined spectral features is evaluated by a separability analysis. This method is performed based on confusion matrices for each material computed from classification results. For comparison this analysis is also performed for material-specific gray values of selected bands. The obtained commission and omission errors show superiority of the spectral features compared to gray values for most of the investigated materials. The results indicate that robust spectral features yield the potential for unsupervised detection of endmembers in hyperspectral image data.
\end{abstract}

Key words: urban surface materials, urban spectral image library, robust spectral features, feature-based techniques, separability analysis, HyMap sensor 


\section{Introduction}

Urban areas are characterized by a large variety of artificial and natural surface materials influencing ecological (Arnold and Gibbons, 1996), climatic and energetic (Oke, 1987) conditions. Knowledge about these materials is required for planning and conservation purposes (Sukopp et al., 1980) as well as for vulnerability analysis (Mueller et al., 2006; Bhaskaran et al., 2001). The dynamic development of urban areas requires frequent updating of existing databases. Standard approaches are mostly based on field investigations and visual interpretation of aerial photographs. Since they are time-consuming and expensive, mapping activities often cannot keep up with the pace of urban development. Thus, there is a big need for the development of innovative methods allowing automated identification of urban surface materials.

During the last years methods for automated acquisition of urban surface materials have been developed using aerial photographs (Tellez and Servigne, 1998) and multispectral data of very high spatial resolution based on object-oriented methods (Meinel et al., 2001; Caprioli and Tarantino, 2003; De Kok et al., 2003). Methods for semiautomated analysis have also been applied incorporating a wide range of context information (Stuckens et al., 2003). New opportunities have been opened up with the availability of airborne hyperspectral remote sensing data characterized by a high spatial and spectral information content. Several studies show the basic potential and new challenges of such data for spectral differentiation of urban surface materials (Ben-Dor, 2001; Heiden et al., 2001a; Roberts and Herold, 2004).

Using hyperspectral remote sensing data requires new methods for data analysis as well as a profound knowledge of spectral characteristics for the relevant materials. In Roessner et al. (2001) a new approach for analyzing airborne hyperspectral data (Digital Airborne Imaging Spectrometer - DAIS) was presented. It combines advantages of classification with linear spectral unmixing based on a pixel-oriented procedure for endmember selection. Spectral differentiation with sub-pixel accuracy was possible between 38 spectrally distinct classes. This approach was extended by the fusion of spectral and shape features using DAIS data in reflective and thermal wavelength ranges (Segl et al., 2003) allowing a better differentiation between roof materials and spectrally similar impervious open surfaces. In these studies problems mainly occurred due to the rather large pixel size $(6 \mathrm{~m})$ and the relatively low signal-to-noise ratio (SNR) of the DAIS data resulting in a high percentage of mixed pixels and a limited representation of spectral features.

In Heiden et al. (2001a) hyperspectral HyMap data of higher spatial resolution and of high SNR were used allowing the identification of less pronounced spectral features. This way, a wider range of materials consisting of 79 spec- 
trally distinct classes could be identified. Successful identification of surface materials in hyperspectral image data requires detailed knowledge about the spectral characteristics of urban surfaces. For this purpose in a number of spectroscopic studies laboratory and field investigations have been carried out (Ben-Dor, 2001; Heiden et al., 2001b; Herold et al., 2004). They have revealed the great spectral variability of urban surface materials as well as the necessity of relating this knowledge to the analysis of hyperspectral image data as an important prerequisite for an automated identification of urban surface materials.

The representation of urban surface materials in hyperspectral image data is also characterized by a high within-class variability (Lacherade et al., 2005; Heiden et al., 2005). This is due to several factors, such as color, coating, degradation and illumination of the material as well as preprocessing of the image data. The highest number of spectrally distinct materials and the greatest variability can be found for roof materials. This is caused by the wide range of available roofing materials and varying orientations of the roofs towards the sun and the sensor. Meister and Rothkirch (1997) have analyzed the bidirectional behavior of roofs taking into account four different look directions for modeling the BRDF (Bidirectional Reflectance Distribution Function). Besides the BRDF effects the often unknown roof inclination has an even greater influence on the spectral variability of roof materials (Meister et al., 2000). Using several parametric, non-parametric and hybrid atmospheric correction methods Ben-Dor et al. (2001) found that atmospheric attenuation is another important factor varying reflectance data of hyperspectral imagery.

Because of this high spectral variability, manual definition of training data or endmembers represents a difficult and time consuming process. In order to assist automated endmember selection, techniques such as PPI (Boardman et al., 1995), N-Finder (Winter, 1999), ORASIS (Bowles et al., 1995), IEA (Staenz et al., 1995), and AMEE (Plaza et al., 2002) were developed. These techniques select the purest pixels based on the analysis of spectral patterns within the image hypercube or, in case of AMEE, in combination with a spatial pattern analysis. All of them are unsupervised techniques and the resulting endmember spectra still have to be assigned interactively to a corresponding surface material. Therefore, such techniques only represent a partial improvement.

In this connection imaging spectroscopy approaches using various spectral features are promising. Van der Meer (2004) applied a linear interpolation method to estimate absorption band parameters from hyperspectral imagery. This approach does not require prior knowledge of the surface cover. Clark et al. (1990) developed an algorithm to measure the fit of a reference spectrum (laboratory) to the observed image spectrum (AVIRIS data). The algorithm uses band ratios, band depth analysis and least-squares fits to evaluate such spectral similarities. This technique was further improved by the development 
of an new algorithm for mapping various minerals based on multiple spectral features (Clark et al., 1991). All of these methods were combined in the Tricorder (Clark and Swayze, 1995) and Tetracorder algorithms (Clark et al., 2003). They identify materials by comparing an unknown spectrum to a large library of field spectra that are characterized by distinct spectral features in well defined diagnostic absorption regions.

Spectral features represent an important prerequisite for an automated material identification in hyperspectral image data. Because of the described high spectral variability of urban surfaces, spectral investigations need to be extended from field measurements to a comprehensive analysis of image spectra. The objective of this study is the development of an approach allowing the image-based derivation of material-specific spectral features that are robust against within class variability and spectral overlap between classes of interest. Such features can be used for automated identification of endmembers in hyperspectral imagery.

\section{Study area, hyperspectral image data and preprocessing}

Test sites were chosen in the two German cities Dresden and Potsdam in order to build a comprehensive spectral library of image spectra. Such a library contains a wide range of diverse urban surface materials including their spectral variability. Test sites comprise a variety of typical urban structures, such as residential quarters, industrial zones, railway stations and recreational areas. They cover north to south transects of about 3 by $10 \mathrm{~km}$ in Dresden and 3 by $16 \mathrm{~km}$ in Potsdam. For the city of Dresden hyperspectral image data were acquired in three different years with acquisition dates between May and August. This way annual and seasonal differences of the urban surface materials due to changes in vegetation development and illumination conditions could be captured in their effect on spectral variability. The details of the different flight missions are listed in Table 1.

The test sites were recorded by the hyperspectral HyMap sensor that was operated by the German Aerospace Center (DLR). The instrument has recorded image data in 128 (1999 data takes) and 126 (2000 and 2003 data takes) spectral bands throughout the visible (VIS), near infrared (NIR) and short wave infrared (SWIR I + II) wavelength ranges. Table 2 shows the sensor characteristics of the HyMap instrument (Cocks et al., 1998). The HyMap sensor operates in a 3-axis gyro stabilized platform to minimize image distortion due to aircraft motion. Remaining motions were recorded during the flight.

Preprocessing of the hyperspectral HyMap data was performed in three steps. First, Integrated Spectronics Pty Ltd carried out on board radiometric and 
Table 1

Flight mission details

\begin{tabular}{|c|c|c|c|c|c|c|}
\hline Date & Time [UTC] & Test site & $\begin{array}{c}\text { Flight } \\
\text { heading }\left[{ }^{\circ}\right]\end{array}$ & $\begin{array}{c}\text { Flight } \\
\text { altitude [m] }\end{array}$ & $\begin{array}{c}\text { Resampled } \\
\text { pixel size }\end{array}$ & $\begin{array}{c}\text { No. of } \\
\text { bands }\end{array}$ \\
\hline 18.05 .1999 & $10: 45$ & Dresden & 179 & 2540 & 6 & 128 \\
\hline 18.05 .1999 & $12: 50$ & Potsdam & 180 & 2560 & 6 & 128 \\
\hline 01.08 .2000 & $11: 50$ & Dresden & 174 & 1660 & 3 & 126 \\
\hline 20.07 .2003 & $10: 20$ & Dresden & 175 & 1680 & 3 & 126 \\
\hline
\end{tabular}

Table 2

Technical characteristics of the HyMap sensor (Cocks et al., 1998)

\begin{tabular}{|c|c|c|c|c|}
\hline Spectrometer & No. of bands & $\begin{array}{c}\text { Wavelength } \\
\text { range [nm] }\end{array}$ & $\begin{array}{c}\text { Bandwidth } \\
{[\mathbf{n m}]}\end{array}$ & $\begin{array}{c}\text { Detector } \\
\text { material }\end{array}$ \\
\hline VIS & 32 & $400-900$ & 15 & $\mathrm{Si}$ \\
\hline NIR & 32 & $885-1350$ & 16 & $\mathrm{In} \mathrm{Sb}$ \\
\hline SWIR I & 32 & $1400-1800$ & 16 & $\mathrm{In} \mathrm{Sb}$ \\
\hline SWIR II & 32 & $1900-2500$ & 20 & $\mathrm{In} \mathrm{Sb}$ \\
\hline
\end{tabular}

spectral calibration of the HyMap data (Cocks et al., 1998). Second, for standardization purpose the radiance data were transformed to reflectance data. This way, the resulting image spectra are comparable to field spectra. Third, the datasets were geometrically corrected in order to allocate surface materials within additional data. They comprise orthophotos, topographic maps and spectral knowledge obtained in field investigations.

The transformation of radiance to reflectance data was performed using parametric and non-parametric techniques. This way, spectral variability due to different preprocessing techniques as described in (Ben-Dor et al., 2001) was taken into account. The correction of the image data recorded for Potsdam and Dresden in 1999 have been carried out using the non-parametric empirical line approach (Roberts et al., 1986). For this purpose homogeneous calibration targets with a minimum size of $4 \times 9$ pixels were measured on the ground using the ASD field spectrometer. They comprise dark loose chippings, brown soil, red loose chippings and bright cobblestone pavement. In their spectral characteristics they cover almost the full spectral range from bright to dark urban surface materials occurring in the two test sites. The quality of the transformation was checked based on the characteristics of the regression lines and the root mean square error (RMSE). The analysis for selected bands showed that the positions of the calibration targets are close to the regression lines indicating very good results. The resulting spectra were compared to control spectra by a regression analysis showing a strong correlation of input radiance and resulting reflectance.

The atmospheric correction of the HyMap scenes recorded for Dresden in 2000 and 2003 were carried out using an in-house developed hybrid algorithm. It employs the radiative transfer models of MODTRAN (Moderate resolution atmospheric transmission) in order to calculate at-surface reflectance. The algorithm also includes a scan-angle dependent correction due to the large field 
of view (FOV) of $61.3^{\circ}$ of the HyMap sensor and an adjacency effect (diffuse scattering) correction. The resulting spectra were further corrected using field measurements within an empirical line procedure to eliminate spikes occurred in the atmospheric bands.

All HyMap scenes were georeferenced to the topographic map (1:25.000) enabling a correct assignment of field spectra to image spectra. The parametric geocorrection was carried out using GPS (Global Positioning System) coordinates recovering the flight line, the angles of pitch, roll and yaw that were recorded during the flight (Cocks et al., 1998) and a digital elevation model. For the geometric transformation of the scenes of 1999 (6 m pixel size) nearest neighbor resampling was used. Although the use of this technique affects the geometric shape of urban objects, its advantage of preserving spectral information is of higher importance for determining robust spectral features, especially in case of a rather large pixel size. The higher spatial resolution of the HyMap scenes of the years 2000 and 2003 (3 m) leads to a higher number of spectrally pure pixels allowing resampling based on the bilinear interpolation method. The obtained mean positional accuracy amounts to $7.7 \mathrm{~m}$ for Dresden (1999), $4.0 \mathrm{~m}$ for Potsdam (1999), $3.3 \mathrm{~m}$ for Dresden (2000) and 3.5 $\mathrm{m}$ for Dresden (2003) datasets. The order of magnitude of these accuracies is acceptable since it approximately corresponds to the size of one pixel.

\section{Spectral data acquisition}

The use of spectral features for identification of urban surface materials requires a detailed knowledge of their spectral characteristics. Section 3.1 reviews existing urban spectral libraries and derives the necessity for developing a new comprehensive library that addresses the specific surface conditions of German cities. Section 3.2 describes the urban surface cover types that result from a categorization of surface materials commonly used in Germany. In section 3.3 the creation of the spectral library containing field measurements (FISL) is described focussing on impervious and partially impervious surfaces. The resulting library is mainly used for identification of unknown materials in the image data and better understanding of the variability of the image spectra. Section 3.4 deals with the development of the image spectral library (HYSL) based on the available multitemporal hyperspectral HyMap data. This library comprises all important surface materials that are relevant for an area-wide classification of German urban areas. 


\subsection{Existing urban spectral libraries}

Spectral libraries form the basis for a comprehensive material-oriented investigation of typical spectral features. Such libraries have been successfully established for geological studies analyzing the spectral signatures of minerals in the reflective (Cloutis, 1996; Hunt and Salisbury, 1970) and in the thermal wavelength ranges (Christensen et al., 2000). In contrast, spectral libraries of urban materials are rare. An early example is the analysis by Ormsby (1992) who evaluated natural and man-made features using Landsat5-TM data in the area of Washington, D.C., USA. He distinguished 9 general surface categories containing 21 spectral classes. Singh and Sirohi (1995) analyzed the reflectance properties of selected road materials in the wavelength range from $450 \mathrm{~nm}$ - $900 \mathrm{~nm}$ based on satellite-simulated reflectance data.

First hyperspectral databases for urban areas were developed by Price (1995), Ben-Dor et al. (2001) and Heiden et al. (2001b). In Heiden et al. (2001b) a first overview of the spectral diversity of surface materials occurring in the city of Dresden, Germany, was given. Ben-Dor et al. (2001) investigated the spectral based recognition of urban surface materials in Tel-Aviv, Israel, using the visible (VIS) and near-infrared (NIR) spectral region (400 nm - 1100 $\mathrm{nm}$ ). Spectra were acquired from spectral measurements in the city of TelAviv, Israel, and the existing database of Price (1995). In a further study, this spectral library was extended to cover the entire VIS-NIR-SWIR wavelength range (Ben-Dor, 2001). Other studies have been carried out in north American cities (Herold et al., 2004; Hook, 1998). Herold et al. (2004) developed a comprehensive field spectral library for the urban region of Santa Barbara and Goleta, CA, USA. The ASTER spectral library developed by Hook (1998) is a compilation of natural and man made materials and includes data from the Johns Hopkins University (JHU) spectral library, the Jet Propulsion Laboratory (JPL) spectral library, and the United States Geological Survey (USGS - Reston) spectral library.

Although the existing urban libraries cover the whole spectral range of interest, they are still not sufficient for analyzing German cities, since some materials are missing and others are not characteristic. For example, the study by Herold et al. (2004) showed, that composite shingle roofs form a large group of roof materials in the investigated Californian area. Their spectral behavior is determined by silicate and hydrocarbon absorption features and mostly varies in dependence on their colors. In German cities, most commonly used materials are roofing tiles. Furthermore, roof materials such as polyvinyl chloride, polyethylene and plexiglass are used. Under these conditions the establishment of a new spectral library is required for the assessment of spectral characteristics of urban surface materials occurring in Germany. 


\subsection{Categorization of German urban surface materials}

In Germany ecological urban mapping based on visual interpretation of aerial photographs has been performed regularly for most of the bigger cities for the last 20 years. For this purpose a detailed and complex mapping key has been developed (Sukopp et al., 1980) allowing a systematic assessment of urban structure types. They are characterized by a number of parameters including the capability of the various materials to infiltrate surface runoff. This aspect has formed the basis for the development of a hierarchical system categorizing urban surface cover types (Roessner et al., 2001). The system was adapted for this study in order to perform a comprehensive assessment of the different urban surface materials in a spectral library (Fig. 1). On the first level (I) urban surfaces are subdivided into impervious and pervious surfaces. Further differentiation of impervious surfaces results in open and overbuilt areas (level II). The latter ones are further characterized by their roofs (level III). Impervious open areas are subdivided into fully and partially impervious open areas (level III). The categories of pervious surfaces (level I) contain non-vegetated and vegetated areas (level II). The latter ones are further differentiated into green spaces (meadows and lawns) and tree/bush-type vegetation. Non-vegetated areas are distinguished into bare soil and water (rivers, lakes or ponds). The categories of level III form the thematic frame for the assessment of urban surface materials (level IV) that are the basis for the spectral investigations in this paper.



Fig. 1. Hierarchical categorization of urban surface materials 


\subsection{Assessment of field spectra}

All field measurements were performed using a field spectrometer (Analytical Spectral Device (ASD) Field Spec Pro FR) with a fore optic lens of $8^{\circ}$ and a spectralon panel (Halon) as white reference. The ASD records data in 2151 bands in the wavelength range between $0.35 \mu \mathrm{m}$ and $2.50 \mu \mathrm{m}$ using three integrated spectrometers. The sampling interval ranges from $1.4 \mathrm{~nm}$ in the VIS/NIR region and $2 \mathrm{~nm}$ in the SWIR region resulting in a spectral resolution of $3 \mathrm{~nm}$ (VIS/NIR) and $10 \mathrm{~nm}$ (SWIR).

Spectral reflectance measurements of all fully and partially impervious open areas were recorded for representative surfaces in the test sites of Potsdam and Dresden, Germany. Material information were acquired based on field inspections and aerial photographs. In-situ measurements of roofs were not possible in the test sites due to their inaccessibility. Therefore, samples of the various roofing materials characterized by different degrees of degradation and different coatings were collected and measured under open sky and direct sun illumination in nadir position. All spectral field measurements were stored in a spectral library (FISL). Table 3 contains the measured materials, their color and their spectrally relevant chemical compounds. The materials have been further categorized into mineral, metallic and hydrocarbon groups.

\subsection{Assessment of image spectra}

The materials contained in the field library were identified in the hyperspectral HyMap data of Dresden and Potsdam, Germany. The resulting spectra form the image library (HYSL). For each material many target locations were identified in the image data from 1999 to 2003. The selection of the image spectra has been performed in an interactive way including additional information, such as the results of field investigations, the field spectral library and color infrared aerial imagery. The goal was to identify target areas that represent the materials of interest as homogeneously as possible. The resulting pixels are regarded as spectrally pure pixels. However, due to the spatial resolution of the image data and the natural variability of the surfaces the purity that can be achieved is limited in comparison to laboratory investigations. Thus, a high number of image spectra was determined with the goal of covering the existing variation for each material caused by different illumination angles and material conditions (e.g. age). Such variations are suppressed by techniques for automated endmember identification, such as the pixel purity index (PPI), where only extreme spectra, mostly the brightest and the darkest endmember of a material are detected.

Based on the available HyMap data, 21670 image spectra have been deter- 
Table 3

Materials of fully and partially impervious surfaces and their spectrally relevant chemical compounds

\begin{tabular}{|c|c|c|}
\hline Material & Surface color & Description \\
\hline \multicolumn{3}{|l|}{ I. Roof materials } \\
\hline \multicolumn{3}{|l|}{ Mineral } \\
\hline - roofing tile & red & $\begin{array}{l}\text { basic material: clay minerals (kaolinite, montmorillion- } \\
\text { ite), quartz, ferric oxides }\left(\mathrm{Fe}_{2} \mathrm{O}_{3}\right) \text {; colored with clay } \\
\text { sludges (containing ferric oxides) before the firing pro- } \\
\text { cess }\end{array}$ \\
\hline \multirow[t]{2}{*}{ - concrete } & gray & $\begin{array}{l}\text { basic material: water, cement }\left(\mathrm{CaO} \times \mathrm{SiO}_{2}, \mathrm{CaO} \times\right. \\
\left.\mathrm{Al}_{2} \mathrm{O}_{3}, \mathrm{CaO} \times \mathrm{Al}_{2} \mathrm{O}_{3} \times \mathrm{Fe}_{2} \mathrm{O}_{3}\right)\end{array}$ \\
\hline & red & $\begin{array}{l}\text { covered with synthetic color; also possible: clay sludges } \\
\text { (containing ferric oxides) after the drying }\end{array}$ \\
\hline - fiber cement & bright/gray & mixture of fibers of synthetics and cellulose, cement \\
\hline - gravel & bright/various & $\begin{array}{l}\text { different pieces of round igneous rocks }(3 \mathrm{~cm} \text { in diam- } \\
\text { eter) }\end{array}$ \\
\hline - slate & black & $\begin{array}{l}\text { flat plates of schist, layer silicates, some sericite, chlo- } \\
\text { rite }\end{array}$ \\
\hline \multicolumn{3}{|r|}{ he } \\
\hline \multirow{2}{*}{ - aluminum } & blank & plates of pure aluminum \\
\hline & red/white & coated with synthetic colors \\
\hline$-\operatorname{zinc}$ & blank & plates of pure zinc \\
\hline - copper & & plates of pure copper (without patina) \\
\hline - lead & & plates of pure lead \\
\hline \multicolumn{3}{|l|}{ Hydrocarbons } \\
\hline \multirow[t]{3}{*}{ - bitumen } & green/gray & $\begin{array}{l}\text { long-chained hydrocarbons (residue of distillation of } \\
\text { petroleum); strewed with crushed slate }\end{array}$ \\
\hline & & covered with red synthetic color \\
\hline & gray & covered with sand \\
\hline - tar paper & dark/gray & $\begin{array}{l}\text { long-chained hydrocarbons (residue of desolation of } \\
\text { hard coal tar); strewed with crushed slate }\end{array}$ \\
\hline - polyvinyl chloride (PVC) & gray & $\mathrm{nCH}_{2}=\mathrm{CHCl} \longrightarrow\left[-\mathrm{CH}_{2}-\mathrm{CHCl}-\right]_{n}$ \\
\hline - polyethylene (PE) & white & $\mathrm{nCH}_{2}=\mathrm{CH}_{2} \longrightarrow\left[-\mathrm{CH}_{2}-\mathrm{CH}_{2}-\right]_{n}$ \\
\hline - polyisobutylene (PIB) & black & $\left(\mathrm{C}_{4} \mathrm{H}_{8}\right)_{n}$ \\
\hline \multicolumn{3}{|c|}{ II. Impervious open surfaces } \\
\hline \multicolumn{3}{|l|}{ Mineral } \\
\hline - concrete & bright/gray & see roofing concrete \\
\hline \multicolumn{3}{|l|}{ Hydrocarbons } \\
\hline - asphalt & dark/gray & $\begin{array}{l}\text { bitumen (mostly long-chained hydrocarbons) mixed } \\
\text { with mineral grains (natural like sand and gravel, syn- } \\
\text { thetic like from waste incineration and blast furnace } \\
\text { slag) }\end{array}$ \\
\hline \multicolumn{3}{|c|}{ III. Partially impervious open surfaces } \\
\hline \multicolumn{3}{|l|}{ Mineral } \\
\hline - cobblestone pavement & various & $\begin{array}{l}\text { different types of igneous rocks (mainly granite), spac- } \\
\text { ings between single stones are filled with sand }\end{array}$ \\
\hline \multirow[t]{2}{*}{ - pavement of concrete } & bright/gray & single pieces of concrete \\
\hline & red & $\begin{array}{l}\text { single pieces of concrete, covered with mineral color } \\
\text { containing iron bearing minerals }\left(\mathrm{Fe}_{2} \mathrm{O}_{3}\right)\end{array}$ \\
\hline - loose chippings & $\begin{array}{l}\text { bright } \\
\text { red }\end{array}$ & $\begin{array}{l}\text { rich in calcite and clay, very fine loose material } \\
\text { crushed tiles (flour of tiles) }\end{array}$ \\
\hline Hydrocarbons & & \\
\hline - loose chippings & black & $\begin{array}{l}\text { mixture from blast furnace slag, mineral grains and } \\
\text { other dark sand }\end{array}$ \\
\hline
\end{tabular}

mined for urban surface materials and stored in the image library (HYSL). These spectra have been assigned to material categories that match with level IV of the system for categorizing urban surface cover types described in section 3.2 (Fig. 1). The HYSL contains 32 categories comprising 21 fully and par- 
tially impervious materials, 9 pervious materials and 2 categories of shadow. They are listed in Table 4 . The roofing materials slate, copper and lead were excluded due to a statistically non relevant sample size. Spectral characteristics of pervious surfaces, such as vegetation and bare soils have already been widely investigated (Chabrillat et al., 2002; Gao and Goetz, 1995; Lawrence et al., 1994; Leone and Sommer, 2000; Thiemann and Kaufmann, 2002). They were assessed as additional input spectra for the separability analysis (section $4.3)$.

The image spectra were subdivided in a training (13925 spectra) and a control (7745 spectra) dataset to analyze the robustness of the identified spectral features within the separability analysis. The training dataset contains all image spectra of the three flight lines of Dresden 1999, Potsdam 1999 and Dresden 2000. The control dataset is composed of image spectra obtained from the flight line Dresden 2003, since this is an independent data take of the test site containing the largest variety of surface materials. Additionally, the dataset has been acquired with a ground sampling of $3 \mathrm{~m}$ making it most suitable as a control dataset. Table 4 shows the number of spectra within the training and control datasets for each material.

Table 4

Image library (HYSL) based on hyperspectral HyMap data

\begin{tabular}{|c|c|c|c|c|c|}
\hline \multirow[b]{2}{*}{ Material (level 4) } & \multicolumn{2}{|c|}{ No. of spectra } & \multirow[b]{2}{*}{ Material (level 4) } & \multicolumn{2}{|c|}{ No. of spectra } \\
\hline & Training & Control & & Training & Control \\
\hline Buildings/roofs & & & Green spaces & & \\
\hline red roofing tiles (new) & 590 & 325 & intensively maintained lawns & 466 & 561 \\
\hline red roofing tiles (old) & 205 & 234 & non-photosynthetic vegetation & 235 & 209 \\
\hline red concrete & 394 & 391 & fallow land & 189 & 223 \\
\hline gravel & 189 & 107 & & & \\
\hline zinc & 63 & 240 & Trees/bushes & & \\
\hline aluminum & 623 & 209 & deciduous trees & 372 & 375 \\
\hline bright bitumen & 644 & 206 & coniferous trees & 391 & 85 \\
\hline dark bitumen & 205 & 164 & & & \\
\hline red bitumen & 63 & 77 & Bare soil & & \\
\hline tar paper & 293 & 280 & bright sand & 311 & 35 \\
\hline polyvinyl chloride (PVC) & 664 & 293 & dark sand & 317 & 85 \\
\hline polyethylene (PE) & 391 & 166 & & & \\
\hline plexiglass & 72 & 57 & Water & & \\
\hline & & & lake & 1329 & 692 \\
\hline $\begin{array}{l}\text { Fully impervious } \\
\text { open spaces }\end{array}$ & & & river & 1928 & 1042 \\
\hline asphalt & 822 & 416 & Shadow & & \\
\hline concrete & 164 & 80 & on vegetated areas & 188 & 50 \\
\hline red tartan & 42 & 75 & on non-vegetated areas & 384 & 72 \\
\hline $\begin{array}{l}\text { Partially impervious } \\
\text { open spaces }\end{array}$ & & & & & \\
\hline cobblestone pavement & 465 & 408 & & & \\
\hline red pavement of concrete & 75 & 48 & & & \\
\hline red loose chippings & 1078 & 244 & & & \\
\hline bright loose chippings & 206 & 66 & & & \\
\hline dark loose chippings & 567 & 230 & & & \\
\hline
\end{tabular}




\section{Approach for determination of robust spectral features}

Existing imaging spectroscopy studies include single and multiple featurebased methods. In section 4.1 these methods are discussed with regard to their usefulness for urban studies. Based on this review we have developed an approach that consists of two parts. First, for each material of interest spectral features (SF) are defined that allow an optimal identification and separation based on the reference spectra contained in the HYSL (section 4.2). In this study, a spectral feature (SF) represents a specific spectral behavior within two wavelength positions in the reflective part of the electromagnetic spectrum. Relevant spectral features are described numerically using feature functions. In the second part (section 4.3), the robustness of these spectral features is evaluated by a separability analysis. For this purpose a method is developed based on an evaluation of other approaches known from the literature. To evaluate the potential of SF for an automated identification of urban surface materials, gray values (GV) are analyzed for comparison with results obtained for spectral features. In contrast to SF, GV are defined in this study as single spectral wavelength positions (spectral bands) in the electromagnetic spectrum.

\subsection{Background}

Since electronic and vibrational processes dominate the spectral reflectance shapes of materials, the absorption band is one of the most important spectral feature used in imaging spectroscopy (Hunt, 1977). An absorption feature can be represented by a local spectral minimum, such as for alunite with an intense absorption band at $2.17 \mu \mathrm{m}$ (Swayze et al., 2003). It can also results in a local convex shape characteristic of the spectrum caused by superimposition of a stronger absorption feature. The occurrence of absorption features and their position in the electromagnetic spectrum give valuable information about the chemical composition of a material. A comprehensive overview of electronic and vibrational processes and their effects is given in (Clark and Englert, 1993; Clark, 1999; Pieters and Englert, 1993). An absorption band can be described by characteristics, such as the position, depth, width and asymmetry (Clark and Roush, 1984; Clark, 1999; Van der Meer, 2004).

Another commonly used feature is the increase in reflectance. One example is the characterization of vegetation based on the increase of reflectance between the red and near-infrared wavelength region as a result of chlorophyll content (Walter-Shea and Norman, 1991). This so called "red edge" can be described by the function of the Normalized Difference Vegetation Index (NDVI). There

are various other specific indices for soil, water and vegetation (Bannari et al., 
Functions of an absorption band and indices are used in single feature-based techniques that are often applied for quantification purposes. One example is described in Krueger et al. (1998), where the relative depth of absorption at $2200 \mathrm{~nm}$ was correlated with the kaolinite content of overburden dumps. A multiple feature-based technique is the continuum removal that highlights several absorption characteristics (Clark, 1999). The obtained absorption features can be used for classification purposes, e.g. within the Multi Range Spectral Feature Fitting (SFF) algorithm or the Tetracorder technique (Clark et al., 2003). However, these single and multiple feature-based techniques consider only one type of feature, e.g. absorption band or indices. Due to the wide range of materials and variations, it is necessary to consider all possible diagnostic spectral properties. Therefore, our approach aims at material-specific combinations of different feature types, such as absorption bands, increase and decrease of reflectance, brightness and continuity of a spectral curve for feature extraction.

\subsection{Determination of spectral features}

The HYSL forms the basis for the determination of spectral features in a two-step process. First, image spectra are related to urban surface materials by comparing them with spectra of the field library and by additional field checks. Characteristics of field measurements and image spectra are compared in order to identify common spectral features that are representative for all image samples of the respective material. This way, the existing variations of the image spectra are taken into account. In this study different types of spectral features are used for material characterization: (1) absorption band, (2) reflectance peak, (3) increase and decrease of reflectance, (4) brightness and (5) continuity of a spectral curve. Second, the obtained spectral features are transformed into numerical values for further computer-based analysis using feature functions. They comprise mean and standard deviation, ratios, area function, absorption position and depth, reflectance height and position as well as offset, gain and RMS (root mean square) of a regression line. All spectral features are calculated between two specific wavelength positions that are interactively defined. The used feature functions are illustrated in Fig. 2.

In this study the position and the depth of an absorption feature is calculated as the difference between the reflectance curve and the hull function within a defined wavelength range (Fig. 2d). Broad absorption bands that are typical for aluminum and zinc, can be better expressed by the area that is enclosed by the reflectance curve between two wavelength positions (Fig. 2c).

Another important feature type is represented by reflectance peaks (local re- 


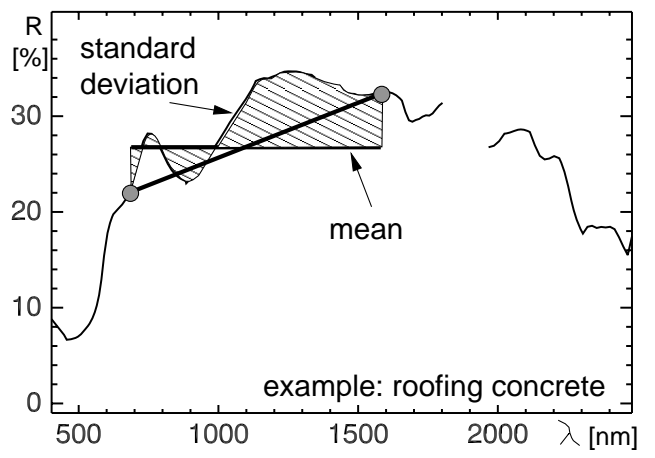

a) Mean and standard deviation

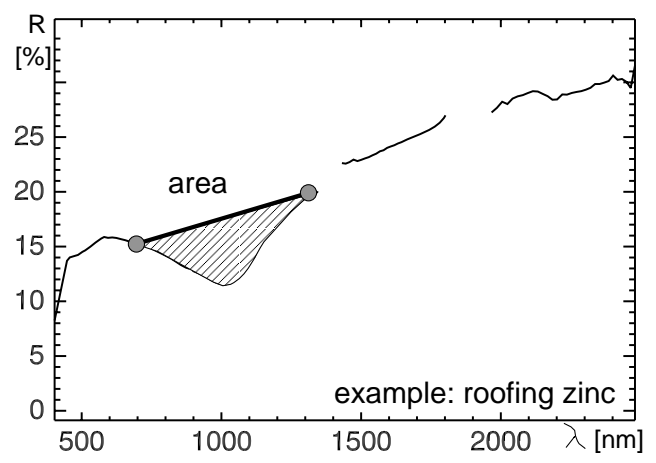

c) Area

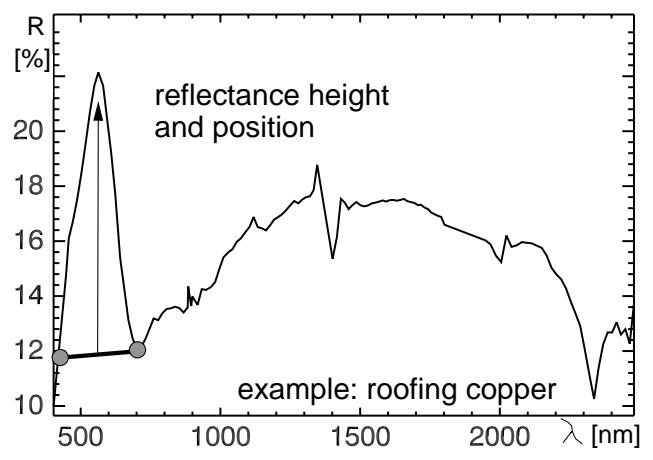

e) Reflectance height and position

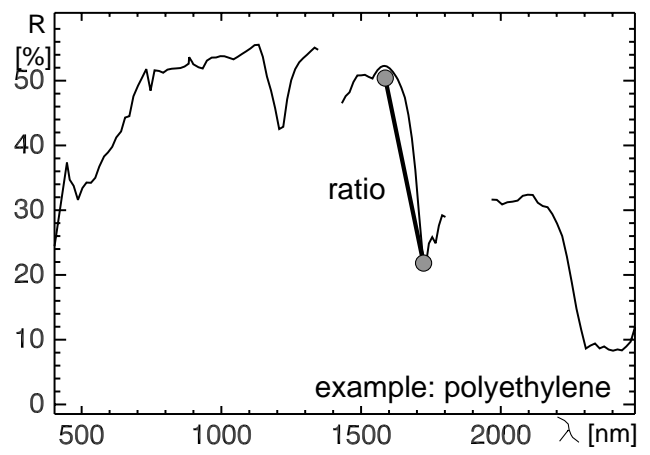

b) Ratio

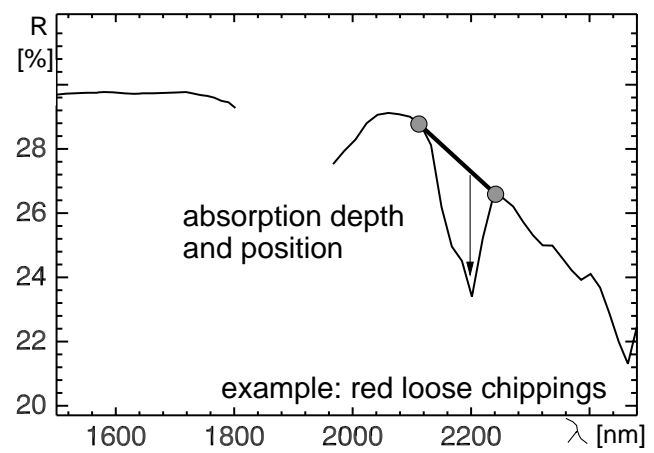

d) Absorption depth and position

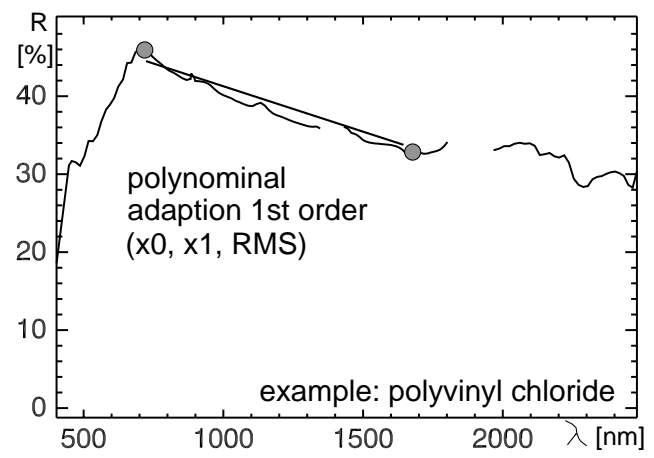

f) Polynominal adaption 1st order

Fig. 2. Feature functions for the numerical description of spectral features; values are calculated between two wavelength bands that are symbolized with a gray point; $\mathrm{R}=$ Reflectance, $\lambda=$ Wavelength

flectance maxima) resulting from two adjacent absorption bands. Fig. 2e shows an example for roofing copper. This feature can be used for the differentiation between e.g. red roofing concrete and red roofing tiles (Table 3). Both materials are characterized by two strong absorption bands in the VIS (445 nm - 622 $\mathrm{nm}$ ) and NIR region (743 nm - $1130 \mathrm{~nm}$ ) that are caused by ferric oxides due to clay sludges used for coloring purposes. The stronger absorption features for red roofing concrete result in a reflectance peak between $862 \mathrm{~nm}$ and 880 $\mathrm{nm}$. This is a distinct feature for a differentiation between both materials. The 
position and the height of the reflectance peak are calculated in the same way as for the absorption feature.

Increase and decrease of reflectance occurring in specific wavelength ranges are also diagnostic feature types. In this study ratios are used for quantification. This way the edges of absorption bands can be described as shown for the absorption feature of polyethylene near $1700 \mathrm{~nm}$ (Fig. 2b).

Another used feature type is the albedo characterizing a specific wavelength range. It is especially important for identification of materials with weak or no spectral absorption features, such as concrete and a number of dark materials. Mean and standard deviation values enable the differentiation between materials with a typical brightness and flat curve progression (Fig. 2a).

The shape of the reflectance curve in a specific wavelength range gives valuable information about a material. A characteristic feature is a constant increase or decrease of reflectance within a specific wavelength range. Fig. $2 \mathrm{f}$ shows such an example for polyvinyl chloride. The obvious constant decrease can be described by three feature types, the gain and offset of a regression line and the root mean square error (RMSE) of a polynomial fit as a measure for the spectral linearity (Fig. 2f).

\subsection{Quantitative analysis of spectral separability}

The previously defined spectral features need to be evaluated in regard to their robustness determining the separability of surface materials. Separability measures most commonly used in remote sensing analyses are distance measures, such as the Transformed Divergence, Jeffries-Matusita and Bhattacharyya distances. However, these techniques have two major disadvantages. First, a quantitative interpretation of the calculated values in regard to an improved classification is impossible. Second, the calculated measure is limited to the separability between two classes. Thus, an overall separability characterizing the spectral overlap of a single material with all other materials occurring in the study area cannot be determined. The following example illustrates this problem. A class shows a good separability with 20 other classes characterized by a constant spectral overlap of $5 \%$ for each class in the feature space. How-

ever, the total spectral overlap can range from $5 \%$ allowing a classification of good quality to $100 \%$ making a classification of this material impossible.

The described limitations of such indices favor the use of confusion matrices computed from classification results. This approach requires the selection of a suitable classifier that can be used for the separability analysis. For such a selection two aspects have to be considered. First, each material is characterized by specific spectral features. None of the existing standard classifier allows a 
meaningful classification based on different number of features and distinct feature types for each class. This problem can be solved by incorporating all possible features for each material in the classification process. However, this leads to a blown-up feature space and to a decrease in accuracy. This means, a separate classifier is used for each material aiming at a distinct separation of this material from all other ones. However, confusion between these other materials can be neglected. For evaluation of their separability confusion matrices are calculated for each material.

The achieved accuracy is measured by overall commission and omission error (Congalton, 1991) representing the potential to classify a specific material. The overall commission error is a value for the percentage of spectra that are included in a class when it should have been excluded. The overall omission error represents the percentage of spectra that is excluded although it should have been included in a class.

A second aspect has to be considered for the selection of a suitable classifier. Since different feature types are taken into account, they have to be normalized in order to be used together. This is not necessary if the features comprise the same type, such as gray values or continuum removed spectra. An optimal normalization of the proposed numerical values representing the spectral features is very complex and requires future investigations. At the present stage of investigations classifiers such as Maximum-Likelihood where normalizing is performed by the covariance matrix or Artificial Neural Networks (e.g. Multi-Layer-Perceptron) are regarded as suitable choices. In our approach the Maximum-Likelihood classifier is used due to its simplicity, general availability and applicability.

Separability is calculated for all of the materials listed in Table 4 containing buildings, fully impervious open spaces, partially impervious open spaces, green spaces, trees/bushes, bare soil, water and shadow. Results are expressed by overall commission errors (ce) and overall omission errors (oe) for each material (Table 5). These errors are calculated for the training dataset (T) to check the used models. They are also calculated for the control dataset (C) allowing the prediction of accuracy for the classification of unknown spectra. In order to get a more detailed impression of the results, the material with the largest and the second largest spectral overlap regarding the classified surface material is shown (Table 6). They are derived for each material from their corresponding confusion matrix using the highest and second highest commission and omission errors.

The described determination of separability for urban surface materials is carried out for the previously derived spectral features (SF). Additionally, the same analysis is applied to gray values (GV). Such data (single spectral bands) are normally used for classification. In this study, gray values are ana- 
lyzed for comparison with results obtained for spectral features. This way the potential of SF and of GV can be evaluated in regard to their suitability for an automated identification of urban surface materials. The used bands are selected according to Herold et al. (2004), where the bands at $445 \mathrm{~nm}, 576$ $\mathrm{nm}, 638 \mathrm{~nm}, 759 \mathrm{~nm}, 1100 \mathrm{~nm}, 1316 \mathrm{~nm}$ and $1989 \mathrm{~nm}$ have been identified as the ones resulting in the best average separability for mapping urban surface materials. These bands were derived using the Bhattacharyya-distance based on individual BT scores (Herold et al., 2004).

\section{Results}

In section 5.1 material-specific spectral features are derived by analyzing hyperspectral HyMap data of the Potsdam 1999, Dresden 1999, Dresden 2000 scenes and respective field spectra. The robustness of these features is evaluated in section 5.2. In section 5.3 results are discussed concerning their implications for an automated identification of urban surface materials in hyperspectral image data.

\subsection{Identification of spectral features in image spectra}

For each of the 21 fully and partially impervious urban surface materials listed in Table 4 distinct spectral features were identified. Fig. 3 and Fig. 4 show the results in an exemplary way. Representative image spectra obtained from each flight line are plotted against field spectra. Fig. 3 and Fig. 4 also contain the number of analyzed image spectra, the specific feature type, the used features functions and the wavelength where the features occur. The wavelength values correspond to the center wavelength of the HyMap bands.

The biggest number of spectral features was found for bright materials, such as polyethylene and roofing tiles. In contrast, some of the dark materials, such as asphalt and roofing tar paper do not show distinct absorption features. Their separation from other materials is only possible based on brightness. Therefore, the feature type brightness was introduced for all materials. It is described by the functions mean and standard deviation. Some examples are now presented in more detail.

In German cities widespread roof materials are hydrocarbons, such as polyvinyl chloride $(P V C)$, polyethylene $(P E)$ and polyisobutylene $(P I B)$ that are mostly used for flat roofs. They are composed of long-chained hydrocarbons (Table 3) and are dominated by $\mathrm{C}-\mathrm{H}$ absorption features starting at $2.20 \mu \mathrm{m}$ and continuing towards the longer wavelengths (Cloutis, 1989). Fig. 3a contains the field spectrum of white PE (fat line). It shows high reflectance values with 


\begin{tabular}{|c|c|c|c|}
\hline $\begin{array}{l}\text { Field spectra (solid line) in comparison with hy- } \\
\text { perspectral image spectra; dotted line = HyMap } \\
\text { data of Dresden 1999, dashed line = HyMap data } \\
\text { of Dresden } 2000 \text {, dash-dots line = HyMap data of } \\
\text { Potsdam } 1999\end{array}$ & $\begin{array}{l}\text { Feature } \\
\text { type }\end{array}$ & $\begin{array}{l}\text { Feature } \\
\text { func- } \\
\text { tion }^{a}\end{array}$ & $\begin{array}{l}\text { Wave- } \\
\text { length } \\
\text { range } \\
{[\mathrm{nm}]}\end{array}$ \\
\hline 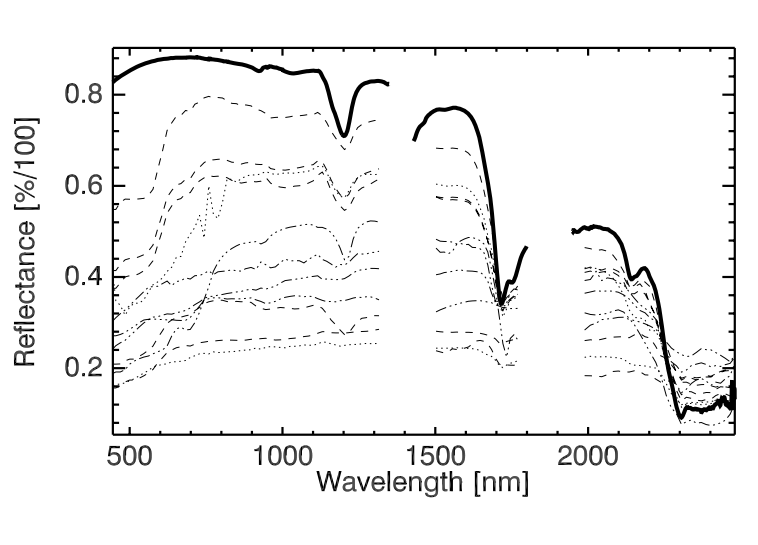 & $\begin{array}{l}\text { a) Polyetl } \\
\text { sample } \\
\text { brightness } \\
\text { increase } \\
\text { decrease } \\
\text { increase } \\
\text { absorption } \\
\text { decrease } \\
\text { absorption } \\
\text { increase } \\
\text { decrease }\end{array}$ & $\begin{array}{l}\text { ene }(391 \\
1,2 \\
3 \\
3 \\
3 \\
4 \\
3 \\
4 \\
3 \\
3\end{array}$ & $\begin{array}{l}\text { ge) } \\
445-2448 \\
486-880 \\
1130-1202 \\
1202-1259 \\
1130-1259 \\
1633-1721 \\
1633-1804 \\
1721-1804 \\
2151-2305\end{array}$ \\
\hline 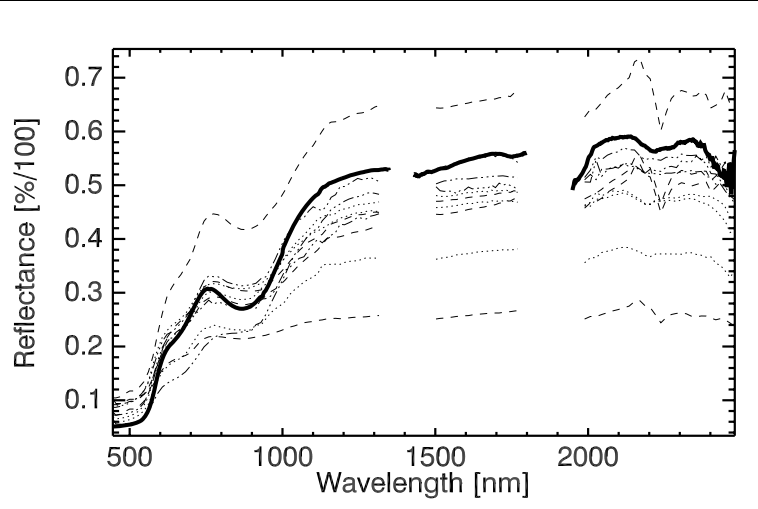 & $\begin{array}{l}\text { b) Roofin } \\
\text { sample } \\
\text { brightness } \\
\text { increase } \\
\text { absorption } \\
\text { absorption } \\
\text { absorption } \\
\text { increase }\end{array}$ & $\begin{array}{l}\text { ile (new) } \\
1,2 \\
3 \\
5,6 \\
5,6 \\
5,6 \\
3\end{array}$ & $\begin{array}{l}\text { (0 image) } \\
445-2448 \\
515-2402 \\
454-622 \\
622-743 \\
758-1130 \\
515-1343\end{array}$ \\
\hline 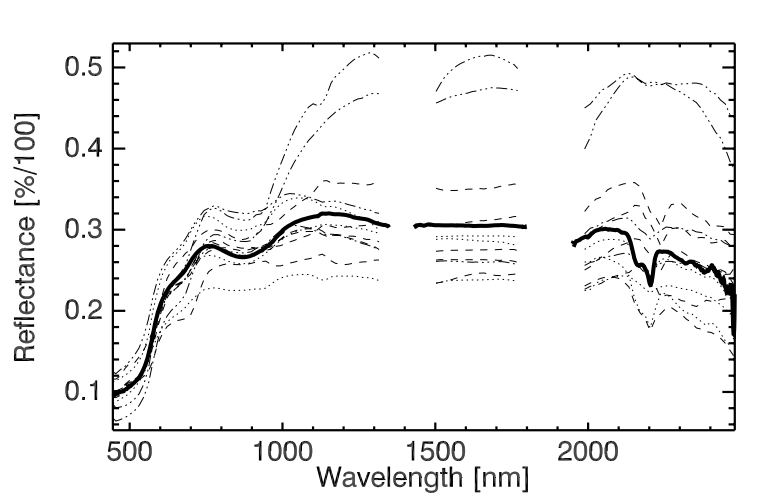 & $\begin{array}{r}\text { c) Red lo } \\
\text { sample } \\
\text { brightness } \\
\text { absorption } \\
\text { absorption } \\
\text { absorption } \\
\text { absorption }\end{array}$ & $\begin{array}{l}\text { chipping } \\
1,2 \\
5,6 \\
5,6 \\
5,6 \\
4\end{array}$ & $\begin{array}{l}078 \text { image) } \\
445-2448 \\
445-607 \\
622-758 \\
773-1085 \\
2134-2272\end{array}$ \\
\hline
\end{tabular}

${ }^{a}$ (1) mean, (2) standard deviation, (3) ratio, (4) area, (5) absorption depth, (6) absorption position,

(7) reflectance height, (8) reflectance position and (9) offset, (10) gain and (11) RMS of a regression line

Fig. 3. Definition of spectral features - example 1 
deep absorption features at $1.2 \mu \mathrm{m}$ and $1.7 \mu \mathrm{m}$ caused by stretch vibrations of the $\mathrm{C}-\mathrm{H}$ compound (Pieters and Englert, 1993). There is a distinct absorption feature at $2.17 \mu \mathrm{m}$ and a sharp decrease of reflectance starting from $2.2 \mu \mathrm{m}$ due to several strong absorption bands beginning at $2.3 \mu \mathrm{m}$ (Cloutis, 1989). Image spectra of PE roofs obtained from all test sites vary widely due to differences in their color consisting of various gray tones. This variety does not affect most of the observed absorption characteristics. The feature at 2.17 $\mu \mathrm{m}$ is an exception that cannot be found in all spectra. Therefore, spectral features were derived for absorption at $1.2 \mu \mathrm{m}$ and at $1.7 \mu \mathrm{m}$ as well as for the increase in reflectance between $486 \mathrm{~nm}$ and $880 \mathrm{~nm}$ and the decrease of reflectance starting from $2151 \mathrm{~nm}$ on. These absorption features are described by the increase and decrease of both shoulders and the enclosed area between them (Fig. 3a).

Roofing tiles and red loose chippings consist of the same base material (Table 3) and thus, are spectrally similar. Field spectra of both materials are characterized by iron absorption bands (Fig. 3b and 3c). They can also be found in image spectra and are described by the absorption depth and position in the wavelength ranges between $445 \mathrm{~nm}$ to $622 \mathrm{~nm}, 622 \mathrm{~nm}$ to $743 \mathrm{~nm}$ and $758 \mathrm{~nm}$ to about $1100 \mathrm{~nm}$. Absorption positions for red loose chippings are slightly shifted in their wavelength ranges (Fig. 3c). Red loose chippings are further characterized by kaolinite absorption features between $2134 \mathrm{~nm}$ and $2272 \mathrm{~nm}$ described by the area function. In general, the albedo of image spectra of red loose chippings is lower than the one for roofing tiles. Therefore, spectral confusion with roofing tiles can occur for tiles of older age that are characterized by weaker iron absorption features and a lower albedo than new roofing tiles.

The separation of new roofing tiles and red loose chippings is based on their different spectral behavior in the SWIR range. In comparison to red loose chippings, roofing tiles are characterized by an increase of reflectance throughout the whole reflective wavelength range that can be quantified by a ratio between reflectance at $515 \mathrm{~nm}$ and $1343 \mathrm{~nm}$ and between reflectance at $515 \mathrm{~nm}$ and $2402 \mathrm{~nm}$. This increase results from the production process of firing causing a loss of water in the material (Heiden et al., 2001b). The decrease of reflectance typical for red loose chippings originates from intensified weathering processes. Since red loose chippings are made of crushed tiles (Table 3), they are characterized by a large surface area that is responsible for increased weathering. This leads to stronger water absorption resulting in a lower albedo in the SWIR II range.

However, image spectra of both materials obtained from data of different years are highly variable. Image spectra of roofing tiles show a strong variability in albedo due to different illumination conditions caused by variations in roof inclination towards the sun. Furthermore, multitemporal effects can be observed due to the different sun angles of the flight lines. Two image spectra of red 
loose chippings identified in the Dresden 1999 dataset show the same spectral characteristics as new roofing tiles. These spectra represent a newly covered lane in a sports stadium that has not been affected by weathering so far.

In Germany, rather new buildings with service functions, such as shopping and recreation are often covered by metal roofs. A commonly used material is pure aluminum that shows a broad and deep absorption band at $0.84 \mu \mathrm{m}$. Zinc shows a similar absorption feature positioned at $1.02 \mu \mathrm{m}$ (Fig. 4a). Multitemporal image spectra of all flight lines show the same spectral features that are described by ratios of the absorption shoulders and the area function. However, image spectra of zinc are characterized by a large variability in albedo. This is caused by specular reflectance that is typical for metallic and glass materials. This process can largely modify spectral reflectance characteristics. Besides the described typical absorption features, additional strong absorption bands appear, if the radiation exceeds the dynamic range of the sensor. In such a case the detector records less energy compared to the real input. Applying an atmospheric correction leads to an underestimation of the resulting reflectance values. They are calculated correctly in the wavelength ranges affected by water vapor absorption, since saturation does not occur in these ranges.

The spectral characteristics of bright roofing bitumen (Fig. 4b) measured by the field spectrometer differ from asphalt (Fig. 4c) due to several absorption bands in the SWIR range. Asphalt shows very weak absorption features and is characterized by a constant slight increase in reflectance. The image spectra of bright bitumen contain a high variability especially in the VNIR wavelength region. This results from different mixed-in materials such as crushed slate or sand that is spread on the base material consisting of long-chained hydrocarbons (Table 3). In the SWIR II range the spectral behavior is caused by various $\mathrm{C}-\mathrm{H}$ stretch overtones and overlapping combination bands (Cloutis, 1989).

Therefore, most of the spectral features were defined in the SWIR wavelength range. They comprise the absorption feature between $1024 \mathrm{~nm}$ and $1259 \mathrm{~nm}$ that is described by the area function, a steady increase of reflectance between $1159 \mathrm{~nm}$ and $1709 \mathrm{~nm}$ described by ratio and parameters of a regression line, a decrease of reflectance between $2116 \mathrm{~nm}$ and $2203 \mathrm{~nm}$ (ratio) and two absorption features starting from $2151 \mathrm{~nm}$. Image spectra of asphalt are characterized by a low albedo and some weak absorption features in the SWIR II wavelength range. Image spectra of the three flight lines differ widely because of different surface conditions, such as deterioration and aging of roads (Herold and Roberts, 2005). Due to the weak absorption features, only overall brightness (mean and standard deviation) and a steady increase of reflectance between $1169 \mathrm{~nm}$ and $1769 \mathrm{~nm}$ expressed by the parameters of a regression line could be identified as typical. However, the low albedo of asphalt result in spectral 


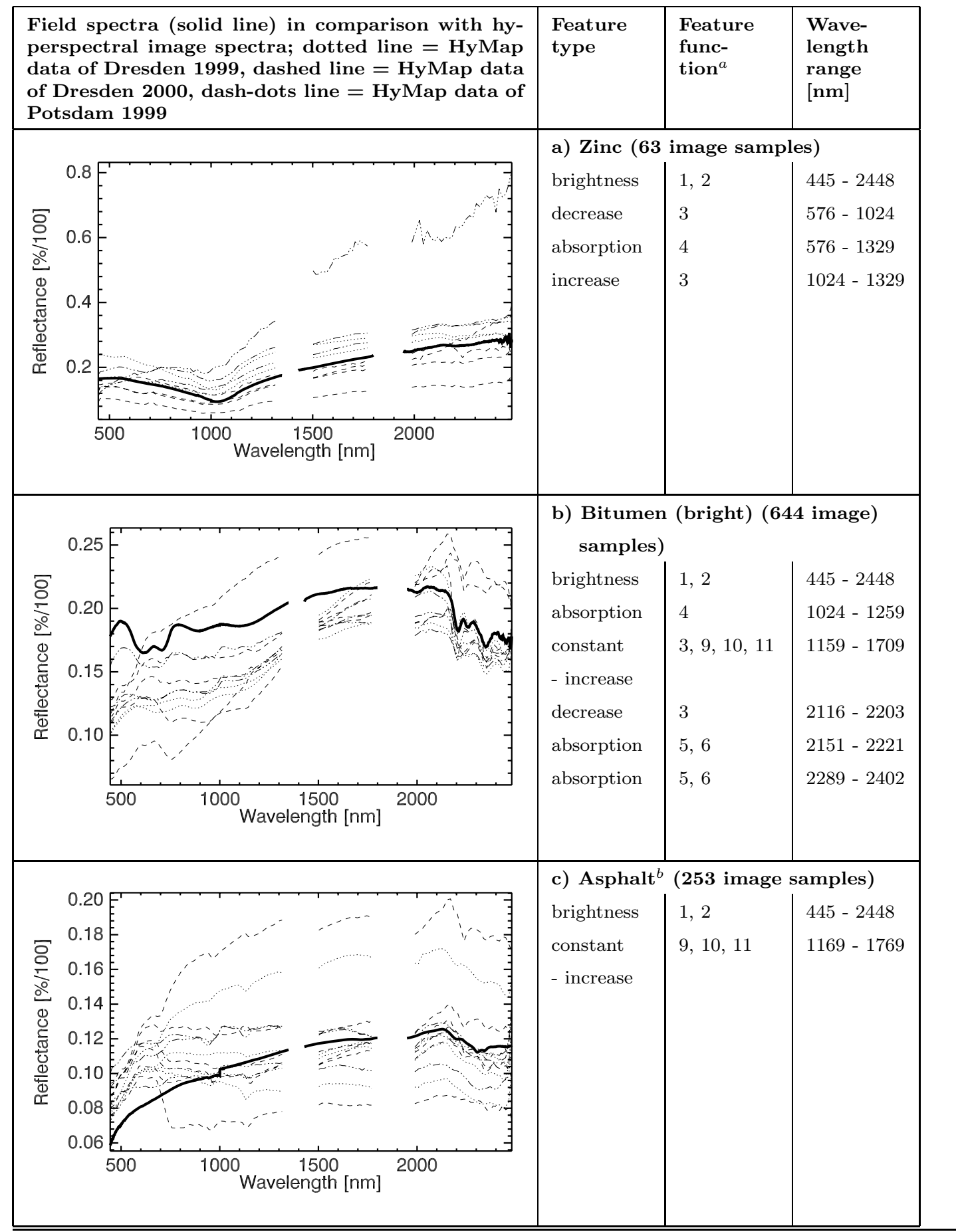

${ }^{a}$ (1) mean, (2) standard deviation, (3) ratio, (4) area, (5) absorption depth, (6) absorption position,

(7) reflectance height, (8) reflectance position and (9) offset, (10) gain and (11) RMS of a regression line ${ }^{b}$ the small step in the reflectance curve of asphalt at about $1000 \mathrm{~nm}$ represents the transition between VNIR and SWIR I detectors in the field spectrometer and thus, is a noise artifact

Fig. 4. Definition of spectral features - example 2 
features that are strongly influenced by noise.

\subsection{Spectral separability of image spectra}

The spectral features identified in section 5.1 are validated with regard to their robustness determining the separability between materials. Table 5 and Table 6 show the results in an exemplary way presenting materials characterized by a behavior that is also common for other materials. Table 5 shows the overall commission and omission errors for the selected materials. In Table 6 highest and second highest commission and omission errors are listed for each material.

Table 5

Overall omission error (oe) and commission error (ce) of each material-specific confusion matrix. T - training data, C - control data, SF - spectral features, GV - gray values

\begin{tabular}{|l||r|r||r|r||r|r||r|r|}
\hline \multicolumn{1}{|l||}{ Material } & \multicolumn{2}{c|}{ T-GV } & \multicolumn{2}{c|}{ T-SF } & \multicolumn{2}{c|}{ C-GV } & \multicolumn{2}{c|}{ C-SF } \\
& oe & ce & oe & ce & oe & ce & oe & ce \\
\hline PE & 8.18 & 13.49 & 0.77 & 2.27 & 15.06 & 64.30 & 4.82 & 7.60 \\
\hline Roofing tiles (new) & 1.36 & 5.21 & 4.07 & 5.03 & 0.00 & 50.91 & 0.00 & 0.00 \\
\hline Roofing tiles (old) & 8.29 & 6.47 & 8.78 & 10.10 & 64.53 & 4.60 & 44.02 & 3.68 \\
\hline Red loose chippings & 8.63 & 1.99 & 15.03 & 2.66 & 4.51 & 45.81 & 4.51 & 35.28 \\
\hline Asphalt & 5.72 & 2.76 & 8.88 & 2.35 & 43.03 & 7.06 & 17.07 & 12.21 \\
\hline Bitumen & 4.04 & 1.59 & 11.34 & 7.75 & 41.26 & 3.97 & 40.78 & 66.11 \\
\hline
\end{tabular}

Polyethylene (PE) is characterized by several distinct spectral features and high spectral variability in the training data containing spectra from low to high albedo. The evaluation of separability of training data based on gray values (GV) shows a spectral confusion of $8 \%$ (overall omission error) with other materials. Another $13 \%$ (overall commission error) of the non-PE spectra were misclassified as PE. Using the spectral features (SF) for the separability analysis, PE could be detected with high accuracy. Only about $1 \%$ of the spectra were misclassified. The control dataset contains even more spectral variations that influence the results. Using SF the overall omission error only amounts to $5 \%$ due to confusion with plexiglass (Table 6 ). Nearly $8 \%$ of other materials, such as plexiglass $(2 \%)$ and aluminum (2\%) were misclassified as PE. The overall omission error for GV is $15 \%$ (aluminum). Furthermore, $15 \%$ of image spectra of red roofing bitumen and $11 \%$ of concrete (Table 6) were classified as $\mathrm{PE}$ resulting in an overall commission error of $64 \%$ (Table 5 ).

Similar results are found for the separability of new roofing tiles. They are characterized by distinct spectral features and a high variability in albedo. For the separability analysis a subset of the spectral features was used excluding the three iron absorption features (section 5.3). Using GV overall omission and commission errors of the training data are very good, only $1 \%$ of the pixels was confused with other materials. Additionally, $5 \%$ of other surface 
Table 6

Maximum and 2nd highest omission errors (oe) and commission errors (ce) of each material-specific confusion matrix. $\mathrm{T}$ - training data, $\mathrm{C}$ - control data, $\mathrm{SF}$ - spectral features, GV - gray values (for explanation of abbreviations see below table)

\begin{tabular}{|ll|r|r|r|r|r|r|r|r|}
\hline Material & & \multicolumn{2}{|c|}{ T-GV } & \multicolumn{2}{|c|}{ T-SF } & \multicolumn{2}{|c|}{ C-GV } & \multicolumn{3}{|c|}{ C-SF } \\
& & $\%$ & material & $\%$ & material & $\%$ & material & $\%$ & material \\
\hline PE & 1. oe & 4.86 & rgra & 0.51 & rgra & 15.06 & ralu & 4.82 & rple \\
& 2. oe & 3.32 & ralu & 0.26 & ralu & 0.00 & & 0.00 & \\
& 1. ce & 2.89 & rbitb & 0.76 & prlc & 14.94 & rbitr & 1.75 & ralu \\
& 2. ce & 1.20 & ralu & 0.50 & rcon & 10.89 & fcon & 1.75 & rple \\
\hline Roofing tiles & 1. oe & 0.51 & ralu & 1.86 & ralu & 0.00 & & 0.00 & \\
(new) & 2. oe & 0.51 & rcon & 0.68 & bsan & 0.00 & & 0.00 & \\
& 1. ce & 3.26 & prlc & 4.70 & prlc & 18.58 & vnpv & 0.00 & \\
& 2. ce & 0.81 & rcon & 0.17 & rtilo & 15.11 & rtilo & 0.00 & \\
\hline Roofing tiles & 1. oe & 2.44 & rtiln & 1.46 & rtiln & 42.74 & rtiln & 22.22 & prlc \\
(old) & 2. oe & 1.46 & rpol & 1.86 & rbitr & 16.24 & rbitd & 7.69 & rzin \\
& 1. ce & 6.47 & prlc & 4.81 & prlc & 3.45 & bsoi & 2.94 & pdlc \\
& 2. ce & 0.00 & & 2.88 & fasp & 1.15 & rple & 0.74 & bsoi \\
\hline Red loose & 1. oe & 2.69 & bsan & 4.08 & bsan & 4.51 & ralu & 2.46 & ralu \\
chippings & 2. oe & 1.86 & rtiln & 2.97 & rgra & 0.00 & & 2.05 & bsan \\
& 1. ce & 0.80 & bsan & 1.17 & rtiln & 17.67 & bsoi & 24.17 & rtilo \\
& 2. ce & 0.50 & rcon & 0.53 & rbitb & 15.81 & ftar & 4.17 & bsoi \\
\hline Asphalt & 1. oe & 3.89 & rtar & 5.72 & rtar & 41.11 & rtar & 15.87 & rtar \\
& 2. oe & 0.61 & rpvc & 1.46 & rbitd & 0.96 & rbitd & 0.48 & rbitb \\
& 1. ce & 1.63 & rtar & 1.30 & rtar & 4.71 & pcob & 6.36 & rtar \\
& 2. ce & 0.63 & rbitb & 0.39 & pcob & 1.96 & rtar & 5.09 & pcob \\
\hline Bitumen & 1. oe & 1.86 & rpol & 3.73 & rpol & 28.16 & rgra & 11.65 & prlc \\
& 2. oe & 0.78 & rbitd & 2.80 & fasp & 6.31 & rtiln & 11.65 & rpol \\
& 1. ce & 0.64 & rbitd & 2.42 & rgra & 3.17 & rgra & 41.67 & pcob \\
& 2. ce & 0.32 & pdlc & 2.26 & fasp & 0.79 & rtar & 10.28 & rgra \\
\hline
\end{tabular}

rgra-roofing gravel, ralu-roofing aluminum, rple-roofing plexiglass, rbitb-roofing bitumen (bright), rbitd-roofing bitumen (dark), rbitr-roofing bitumen (red), rtilo-roofing tiles (old),

rtiln-roofing tiles (new), rzin-roofing zinc, rcon-roofing concrete, rtar-roofing tar paper,

rpvc-roofing PVC, rpol-roofing polyethylene, prlc-red loose chippings, pdlc-dark loose chippings, pcob-cobblestone pavement, fcon-concrete, ftar-tartan, fasp-asphalt, bsan-bright sand,

bsoi-dark sand, wlake-lake, vnpv-nonphotosynthetic vegetation, sveg-shadow on vegetated areas

materials, such as red loose chippings $(3 \%)$ and roofing concrete $(1 \%)$ were classified as roofing tiles. Analyzing SF errors are slightly higher amounting to $4 \%$ of misclassified image spectra of new roofing tiles (omission error). Another $5 \%$ of other image spectra are wrongly classified as new roofing tiles (commission error).

Analyzing the control data, SF show much better results than GV. Although the overall omission errors for both, GV and SF, are $0 \%$, the overall commission error for $\mathrm{GV}$ is about $50 \%$. Among these, around $19 \%$ of image spectra representing non-photosynthetic vegetation and $15 \%$ of the spectra for old roofing tiles were misclassified as new roofing tiles (Table 6). Using SF none of the image spectra characterizing all the other materials was misclassified as new roofing tiles.

Old roofing tiles differ from new roofing tiles in their degree of weathering 
resulting in a lower albedo and weaker spectral features. This affects the separability of old roofing tiles from other materials. Although the overall omission and commission errors are low for the training data for GV (8\% and $6 \%$ ) and SF (9\% and $10 \%$ ), the results based on the control data show high spectral confusion (Table 5). This is especially the case for materials consisting of similar chemical compounds, such as new roofing tiles and red loose chippings (Table 3). Using GV for separability analysis $43 \%$ of the control image spectra are confused with new roofing tiles and $16 \%$ with dark roofing bitumen (Table 6) resulting in an overall omission error of $65 \%$ (Table 5).

Using SF for separability analysis, spectral confusion could be reduced to an overall value of $44 \%$ (Table 5 ). About $22 \%$ of the image spectra of old roofing tiles were classified as red loose chippings (Table 6) and $8 \%$ as roofing zinc. Confusion with red loose chippings can be expected, since the material consists of crushed tiles. During the fabrication, the surface area of the former tiles is enlarged and thus more exposed to water, dust and moss growth leading to faster weathering. The results of red loose chippings obtained for the control data confirm these observations. Using GV, $46 \%$ of the other image spectra were misclassified as red loose chippings. The other image spectra comprise bare soil $(18 \%)$ and fully impervious tartan (16\%). Separability analysis of control data based on SF show an overall commission error of $35 \%$. In most of the cases $(24 \%)$ old roofing tiles were classified as red loose chippings (Table $6)$.

Asphalt has no specific absorption feature and is characterized by a low albedo covering the whole reflective range. The separability analysis of training data based on GV resulted in low overall omission (6\%) and commission errors (3 $\%)$. The analysis of the control data shows high spectral confusion, the overall omission error rises up to $43 \%$. Confusion occurs with other low albedo materials such as roofing tar paper $(41 \%)$ and dark roofing bitumen $(1 \%)$. Looking at the SF analysis, the use of spectral features obtained by visual analysis was also not successful. Therefore, additional features had to be introduced in order to obtain meaningful results. For the SF analysis of control data gray values used in Herold et al. (2004) were extended and mean values of the following wavelength ranges were used: $445 \mathrm{~nm}-570 \mathrm{~nm}, 576 \mathrm{~nm}-600$ $\mathrm{nm}, 638 \mathrm{~nm}-750 \mathrm{~nm}, 759 \mathrm{~nm}-900 \mathrm{~nm}, 1100 \mathrm{~nm}-1300 \mathrm{~nm}, 1316 \mathrm{~nm}-1816$ $\mathrm{nm}, 1989 \mathrm{~nm}-2400 \mathrm{~nm}$. This way, a broader wavelength range was taken into account. Noise in the data was suppressed by using the mean values of these wavelength ranges. Based on these additional spectral features, the overall omission error could be reduced to $17 \%$. Most of the confusion still occurs with spectrally similar roofing tar paper (16\%) and bright roofing bitumen $(1 \%)$.

Separation of roofing bitumen from other materials is good based on GV analyzing the training data. The overall omission error is $4 \%$ and the overall 
commission error amounts to $2 \%$. The errors for SF indicate a higher spectral confusion (11\%). $8 \%$ of the training data were misclassified as roofing bitumen. Results based on control data for both, GV and SF, show that separation of roofing bitumen from other materials was not successful. Using SF, about $41 \%$ of the control data were misclassified (overall omission error). Spectral confusion occurs with red loose chippings (12\%) and PE (12\%). The overall commission error is about $66 \% .42 \%$ of cobblestone pavement and $10 \%$ of roofing gravel were misclassified as roofing bitumen using the control data. Results based on GV are slightly better, $41 \%$ of the control spectra were misclassified, most of them as roofing gravel $(28 \%)$.

\subsection{Discussion of results}

Image spectra obtained from multitemporal hyperspectral HyMap data of the cities of Dresden and Potsdam in Germany were compared to field spectra in order to assess their spectral fit and variability (section 5.1). This analysis had the goal of identifying spectral features that are present in both type of spectra and thus can be further evaluated in regard to their robustness (section 5.2). Spectral shape is rather similar for both type of spectra for all of the investigated materials. Variations are mainly caused by different albedo characteristics in case of old roofing tiles, illumination in case of new roofing tiles and different colors in case of PE. A large spectral variability was found for old roofing tiles reflecting their different stages of weathering in combination with varying illumination situations. Despite these variations, material-specific absorption features could be identified in both libraries in the whole reflective wavelength range. This confirms the capability of the hyperspectral HyMap sensor to record such spectral characteristics.

However, there are spectral features in field spectra that could not be resolved in all of the image samples. This is caused by several previously described factors, such as preprocessing and illumination. The spectral signal also changes between different multitemporal data takes. Characteristics that are not represented in all of the image samples cannot be used as robust spectral features in an automated classification process. The analysis presented in section 5.1 shows the wide range of possible variations that cannot be covered in field investigations. This variability can only be assessed by a comprehensive image library forming the basis for an automated endmember detection from hyperspectral data.

The results presented in section 5.1 show that urban materials need to be described by more than one type of feature. Materials characterized by distinct absorption features and high albedo can be well described by absorption bands and reflectance peaks using feature functions such as ratio, area and 
absorption depth and position. Materials with weak spectral characteristics and low albedo are described best by the feature type of brightness using mean and standard deviation values of a characteristic wavelength range. The developed approach allows simultaneous consideration of various feature types and enables an appropriate quantitative description of a specific urban surface material on the basis of the presented feature functions.

The robustness of spectral features was evaluated by a separability analysis (section 5.2). For comparison purposes this analysis was also performed for gray values (GV) defined by Herold et al. (2004). The analysis of training data led to similar results for both models. Thus, they are an indicator for the potential of the selected SF and GV for spectral separation of urban surfaces. Analyzing the unknown control spectra, SF are superior to GV for most of the investigated materials. This is especially the case for surface materials with strong spectral characteristics. For PE materials a high spectral variability of albedo is observed especially in the visible and near-infrared wavelength ranges. SF are widely independent from such variations. Using $G V$, varying albedo in the training data could not be fully described leading to unsatisfactory results for the control data.

The commission errors for control spectra of new roofing tiles show again the disadvantage of using GV. The misclassification of about $19 \%$ of nonphotosynthetic vegetation spectra (Table 6) can be explained by the spectral overlap between the control datasets of new roofing tiles and non-photosynthetic vegetation. The overlap occurs in almost all GV positions (section 4.3). Using spectral features, such as brightness and the increase of reflectance over the whole reflectance range instead, overlap was significantly reduced leading to a better separation between both surface materials.

This better separability using SF cannot be observed for dark materials with low reflectance and weak spectral characteristics, such as asphalt and roofing bitumen. However, for these materials the use of GV was not successful either. In case of both materials, noise contained in the image data is dominant compared to the signal leading to a high variability. Therefore, a robust quantitative description of these materials becomes difficult. Due to the lack of broad spectral characteristics, the use of gray value positions is more suitable for the separation between materials of low reflectance. Since GV derived from single bands are especially affected by high noise content, they were calculated for a broader wavelength range minimizing the fraction of spectral noise against the real spectral signal. This way, the overall omission error is lowered, although spectral confusion still occurs in case of spectrally similar materials, such as different kinds of roofing tar paper.

Using the SF technique, it is important to identify unique spectral features. In case of roofing tiles, the interactively determined spectral features needed to be 
revised. Several runs of the separability analysis with varying SF showed that spectral features included in Fig. 3 covering characteristic iron absorptions are also characteristic for other materials, such as red loose chippings. Thus, they are not unique for roofing tiles. A more distinct ratio between $515 \mathrm{~nm}$ and $1343 \mathrm{~nm}$ was introduced instead of the spectral features describing the iron absorption bands.

The results of the separability analysis using the presented approach (section 4.3) allow a realistic evaluation of the overall separability of the considered surface materials and thus, the robustness of the identified spectral features. In practice, results can be treaten as accuracies for a classification of predominantely pure pixels of the investigated materials. It also takes into account other materials occurring in an hyperspectral image scene of urban areas, such as vegetation and shadow. Based on overall omission and commission errors of each material-specific confusion matrix, it was possible to quantify the percentage of confusion of a surface material with all other materials occurring in the dataset (Table 4). Spectral confusion of materials could be evaluated in more detail based on highest and second highest omission and commission errors. These are important information for the derivation of more distinct spectral features allowing an unambiguous separation of urban surface materials.

\section{Conclusion and outlook}

Analysis of the established field and image spectral libraries have revealed a wide range of material specific spectral characteristics for urban surface materials. Image spectra showed a much higher spectral variability than field measurements. This is caused by the natural variability of material properties, illumination conditions and multitemporal data recording. Despite this high variability, common spectral features could be identified that are characteristic for all image spectra of a certain material. Due to the complexity of these spectral features, their quantitative description required the introduction of various feature types, such as absorption feature, increase and decrease of the reflectance curve. They have been evaluated concerning their robustness by a separability analysis showing superiority of the spectral features compared to gray values for most of the investigated materials. This indicates the great potential of the presented spectral features for effective mapping of urban surface materials.

Gray values of single spectral bands are commonly used in standard image analysis techniques for material differentiation. This approach mostly requires the determination of training data for each new image scene because of the high spectral variability of materials contained in one image scene. The re- 
sults presented in this paper show that robust spectral features are widely independent from these variabilities. Therefore, using spectral features as input parameters for an identification process, the establishment of the training database has to be carried out only once.

Successful extraction of robust spectral features requires hyperspectral image data of high spectral quality that contain the spectral characteristics over the whole reflective wavelength range. Additionally, the initial training data base has to be complete containing all existing spectral variations of urban surface materials. In order to satisfy these requirements high quality hyperspectral HyMap data were used. These data were recorded in three different years covering test sites in two large German cities, Dresden and Potsdam. This way, the image data contain a large spectral variability resulting in the selection of more than 21.000 image spectra from the four image scenes. The established image spectral library is regarded as representative for larger cities in Germany.

However, with an increasing number of image scenes, interactive definition of common spectral features becomes more and more difficult. Therefore, future methodological developments need to focus on automated derivation of robust spectral features for the identification of urban surface materials. The feature types presented in this paper will form the basis of such an approach.

The presented method for the derivation of robust spectral features is an important step towards an automated identification of spectrally homogeneous endmembers from hyperspectral image data. Since endmember selection is one of the most crucial steps in the classification of hyperspectral remote sensing data, the derived spectral features can significantly improve the automated analysis of mixed pixels in a subsequent identification procedure (e.g., spectral unmixing or classification). Optimal use of the material-specific features for automated mapping purposes requires the development of new identification methods. Such classifiers need to be able to combine the different feature types and handle different numbers of features for each material. The classification procedure must also allow scaling the data in a meaningful way and combining a high number of input values. Future research work will be focused on the development of such a classifier.

The results of this study show the wide range of urban surface materials that can be identified using hyperspectral image data. Since these materials largely influence the infiltration of surface runoff, they are an important parameter for the ecological characterization of urban structure types. Therefore, in Germany these materials are systematically assessed in ecological urban biotope mapping. Due to the need for regular updates the standard methodology based on field investigations and visual interpretation of aerial photographs is very time-consuming. Under these conditions mapping efforts will greatly benefit 
from automated approaches allowing the development of strategies for effective ecological monitoring of large urban areas.

\section{Acknowledgments}

This work was made possible by the flight campaigns in 1999, 2000 and 2003 carried out by the Deutsches Zentrum fuer Luft- und Raumfahrt Oberpfaffenhofen, Germany. The authors would also like to thank Integrated Spectronics Pty Ltd. for system correction and radiometric calibration of the HyMap Data. We wish to acknowledge the reviewers, whose thoughtful comments helped to improve the final manuscript.

\section{References}

Arnold, C. L. J. and C. J. Gibbons, 1996, Impervious Surface Coverage: The emergence of a key environmental indicator. Journal of the American Planning Association 62, 2, 243-258.

Bannari, A., Morin, D., Bonn, F. (1995), A review of vegetation indices. Remote Sensing Reviews, 13, 95-120.

Ben-Dor, E. (2001), Imaging spectrometry for urban applications. In: Van der Meer, F.D., De Jong, S.M. (Eds.), Imaging spectrometry. Basic principles and prospective applications. Kluwer Academic Publishers, Dordrecht.

Ben-Dor, E., Levin, N., Saaroni, H. (2001), A spectral based recognition of the urban environment using the visible and near-infrared spectral region (0.4-1.1 $\mu \mathrm{m})$. A case study over Tel-Aviv. International Journal of Remote Sensing, 22(11), 2193-2218.

Bhaskaran, S., Datt, B., Neal, T., Forster, B. (2001), Hail storm vulnerability assessment by using hyperspectral remote sensing and GIS techniques. Proceedings of the IGARSS symposium, 9.13th July, 2001, Sydney, Australia.

Boardman, J. W., Kruse, F. A., Green, R. O. (1995), Mapping target signatures via partial unmixing of AVIRIS data: in summaries, Fifth JPL Airborne Earth Science Workshop, JPL Publication 95-1,1, 23-26.

Bowles, J., Palmadesso, P. J., Antoniades, J. A., Baumback, M. M., Rickard, L. J. (1995), Use of filter vectors in hyperspectral data analysis, Proc. SPIE Infrared Spaceborne Remote Sensing, III, 148-157.

Caprioli, M., Tarantino, E. (2003), Urban features recognition from VHR satellite data with an object-oriented approach. Proceedings of Commission IV Joint Workshop (CD-ROM), Challenges in Geospatial Analysis, Integration and Visualization II, September 8 - 9, 2003, Stuttgart, Germany.

Chabrillat, S., Goetz, A.F.H., Krosley, L., Olsen, H. W. (2002), Use of hyperspectral images in the identification and mapping of expansive clay soils and the role of spatial resolution. Remote Sensing of Environment, 82, 431-445. 
Clark, R.N., Roush, T.L. (1984), Reflectance spectroscopy: Quantitative Analysis Techniques for Remote Sensing Applications, J. Geophys. Res., 89, 6329-6340.

Clark, R.N., Gallagher, A., Swayze, G.A. (1990), Material absorption band depth mapping of imaging spectrometer data using a complete band shape least-square fit with library reference spectra. Proceedings of the third Airborne Visible/Infrared Imaging Spectrometer (AVIRIS) Workshop, JPL Publication, 176-186.

Clark, R.N., Swayze, G.A., Gallagher, A., Gorelick, N., Kruse, F. (1991), Mapping with Imaging Spectrometer Data Using the complete band shape leastsquares algorithm simultaneously fit to multiple spectral features from multiple materials. Proceedings of the third Airborne Visible/Infrared Imaging Spectrometer (AVIRIS) Workshop, JPL Publication, 91-28, 2-3.

Clark, R.N., Englert, P.A. (1993), Reflectance spectroscopy: quantitative analysis techniques for remote sensing applications. Journal of Geophysical Research, 89(B7), 6329-6340.

Clark, R.N. and Swayze, G.A. (1995), Mapping Minerals, Amorphous Materials, Environmental Materials, Vegetation, Water, Ice and Snow, and Other Materials: The USGS Tricorder Algorithm. Summaries of the Fifth Annual JPL Airborne Earth Science Workshop, January 23- 26, R.O. Green, (Ed.), JPL Publication, 95-1, 39-40.

Clark, R.N. (1999), Spectroscopy of rocks and minerals and principles of spectroscopy. Remote sensing for the earth sciences: Manual of Remote Sensing, 3rd ed., edited by A. N. Rencz, John Wiley and Sons Inc., 3, 3-52.

Clark, R.N., Swayze, G.A., Livo, K.E., Kokaly, R.F., Sutley, S.J., Dalton, J.B., McDougal, R.R., Gent, C.A. (2003), Imaging spectroscopy: Earth and planetary remote sensing with the USGS Tetracorder and expert systems, J. Geophys. Res., 108(E12), 5131, doi:10.1029/2002JE001847.

Cloutis, E.A. (1989), Spectral reflectance properties of hydrocarbons: remotesensing implications. Science, 245, 165-168.

Cloutis, E.A. (1996), Hyperspectral geological remote sensing: evaluation of analytical techniques. International Journal of Remote Sensing, 17(12), 2215-2242.

Christensen, P.R., Bandfield, J.L., Hamilton, V.E., Howard, D.A., Lane, M.D., Piatek, J.L., Ruff, S.W., Stefanov, W.L. (2000), A thermal emission spectral library of rock-forming minerals. Journal of Geophysical Research, 105(E4), 9735-9739.

Cocks, T., Jenssen, R., Stewart, A., Wilson, I., Shields, T. (1998), The HyMap $^{T M}$ airborne hyperspectral sensor: The system, calibration and performance. Proceedings of the 1th EARSeL Workshop in Zurich, 37-42.

Congalton, R.G. (1991), A review of assessing the accuracy of classification of remotely sensed data. Remote Sensing of Environment, 37, 35-46.

De Kok R., Wever T., Fockelmann R. (2003), Analysis of urban structure and development applying procedures for automatic mapping of large area data. The International Archives of the Photogrammetry, Remote Sensing and 
Spatial Information Science, CD-ROM, XXXIV-7/W9, Regensburg, Germany, 27-29 June 2003.

Gao, B.-C., Goetz, A.F.H. (1995), Retrieval of equivalent water thickness and information related to biochemical components of vegetation canopies from AVIRIS data. Remote Sensing of Environment, 52, 155-162.

Heiden, U., Roessner, S., Segl, K., Kaufmann, H. (2001a), Potential of hyperspectral HyMap data for material oriented identification of urban surfaces. In: Juergens, C. (Ed.) Remote Sensing of Urban Areas, Regensburger Geographische Schriften, 35, Abstracts and Full Papers (on Supplement CDROM) of the 2nd International Symposium of Remote Sensing in Urban Areas, June 2001, Regensburg, Germany.

Heiden, U., Roessner, S., Segl, K., Kaufmann, H. (2001b), Spectral analysis of urban surfaces using field measurements and hyperspectral HyMap data. Proceedings of IEEE/ISPRS Joint Workshop on Remote Sensing and Data Fusion over Urban Areas, Rome, 173-177.

Heiden, U., Segl, K., Roessner, S., Kaufmann, H. (2005), Determination and verification of robust spectral features for an automated classification of sealed urban surfaces. In: Zagajewski, B. and Sobczak, M., (Eds.), 2005, Imaging Spectroscopy. New quality in environmental studies. 165-174.

Herold, M., Roberts, D.A., Gardner, M.E., Dennison, P.E. (2004), Spectrometry for urban area remote sensing - Development and analysis of a spectral library from 350 to $2400 \mathrm{~nm}$. Remote Sensing of Environment, 91, 304-319.

Herold, M., Roberts, D.A. (2005), Spectral characteristics of asphalt road aging and deterioration: implications for remote-sensing applications. Applied Optics, 44 (20), 4327-4334.

Hook, S. J. (1998), ASTER spectral library. URL: http://speclib.jpl.nasa.gov, (access: August 2006).

Hunt, G.R., Salisbury, J.W. (1970), Visible and near-infrared spectra of minerals and rocks: I. Silicate minerals. Modern Geology, 1, 283-300.

Hunt, G.R. (1977), Spectral signatures of particulate minerals in the visible and near infrared. Geophysics, 42(3), 501-513.

Krueger, G., Erzinger, J., Kaufmann, H. (1998), Laboratory and airborne reflectance spectroscopic analyses of lignite overburden dumps. Journal of Geochemical Exploration, 64, 47-65.

Lacherade, S., Miesch, C., Briottet, X., Le Men, H. (2005), Spectral variability and bidirectional reflectance behavior of urban materials at a $20 \mathrm{~cm}$ spatial resolution in the visible and near-infrared wavelength. A case study over Toulouse (France). International Journal of Remote Sensing, 26 (17), 38593866.

Lawrence, W. T., Williams, D. L., Ranson, K. J., Irons, J. R., Walthall, C. L. (1994), Comparative analysis of data acquired by three narrow-band airborne spectroradiometers over subboreal vegetation. Remote Sensing of Environment, 47, 204-215.

Leone, A. P., Sommer, S. (2000), Multivariate analysis of laboratory spectra for the assessment of soil development and soil degradation in the Southern 
Appennines (Italy). Remote Sensing of Environment, 72, 346-359.

Meinel, G., Neubert, M., Reder, J. (2001), The potential use of very high resolution satellite data for urban areas - first experiences with IKONOS data, their classification and application in urban planning and environmental monitoring. In: 2nd International Symposium of Remote Sensing of Urban Areas in Regensburg, Germany, published on CD-ROM.

Meister, G., Rothkirch, A. (1997), BRDF effects in remotely sensed high resolution images of urban areas. In: Proceedings of ISPRS Joint Workshop, Hannover.

Meister, G., Rothkirch, A., Spitzer, H., Bienlein, J. (2000), BRDF field studies for remote sensing of urban areas. Remote Sensing Reviews, 19, 37-57.

Mueller, M., Segl, K., Heiden, U. and Kaufmann, H. (2006). Potential of highresolution satellite data in the context of vulnerability of buildings. Natural Hazards, 38 (1-2), 247-258.

Oke, T.R. (1987), Boundary Layer Climates, Routledge, New York.

Ormsby, J.P. (1992), Evaluation of natural and man-made features using Landsat TM data. International Journal of Remote Sensing, 13 (2), 303318.

Plaza, M., Martinez, P., Peres, R., Plaza, J. (2002), Spatial/spectral endmember extraction by multidimensional morphological operations.

Pieters, C. M., Englert, P. A. (1993), Remote geochemical analysis: elemental and mineralogical composition. Cambridge University Press, 65-67.

Price, J.C. (1995), Examples of high resolution visible to near-infrared reflectance sand a standardized collection for remote sensing studies. International Journal of Remote Sensing, 16, 993-1000.

Roberts, D. A., Yamaguchi, Y., Lyon, R. J. (1986), Comparison of various techniques for calibration of AIS data. Proceedings of Second Airborne Imaging Spectrometer Data Analysis Workshop, 21-30.

Roberts, D. A., Herold, M. (2004), Imaging spectrometry of urban materials. In: King, P., Ramsey, M.S., Swayze, G., (Eds.), 2004. Infrared spectroscopy in geochemistry, exploration and remote sensing. Mineral Association of Canada, Shourt Course Series, London, Ontario, 33, 155-181.

Roessner, S., Segl, K., Heiden, U., Kaufmann, H. (2001), Automated differentiation of urban surfaces based on airborne hyperspectral imagery. IEEE Transactions on Geoscience and Remote Sensing 39(7), 1525-1532.

Segl, K., Roessner, S., Heiden, U., Kaufmann, H. (2003), Fusion of spectral and shape features for identification of urban surface cover types using reflective and thermal data. ISPRS Journal of Photogrammetry and Remote Sensing, 58, 99-112.

Singh, R.P., Sirohi, A. (1995), Spectral reflectance properties of different types of built-up surfaces. Journal of Aerospace Engineering, 8 (1), 25-31.

Staenz, K., Szeredi, T., Schwarz, J. (1998), ISDAS - A system for processing/analyzing hyperspectral data, Canadian Journal of Remote Sensing, 24, 99-113.

Sukopp, H., Kunick, W., Schneider, C. (1980), Biotope mapping in the built- 
up areas of West Berlin. Part II. Field methods and evaluation. Garten Landschaft, 565-569.

Swayze, G.A., Clark, R.N., Goetz, A.F.H., Chrien, T.G., Gorelick, N.S. (2003), Effects of spectrometer band pass. sampling, and signal-to-noise ratio on spectral identification using the Tetracorder algorithm. Journal of Geophysical Research, 108 (E9), 5105, doi:10.1029/2002JE001975.

Stuckens, J., Coppin, P.R., Bauer, M.E. (2000), Integrating Contextual Information with per-Pixel Classification for Improved Land Cover Classification. Remote Sensing of Environment, 71, 282-296.

Tellez, B., Servigne, S. (1998), Updating urban database with aerial photographs: A common structuring methodology. Computers, Environment and Urban Systems, 21(2), 133-145.

Thiemann, S., Kaufmann, H. (2002), Lake water quality monitoring using hyperspectral airborne data - A multitemporal approach. Remote Sensing of Environment, 81(2-3), 228-237.

Van der Meer, F. (2004), Analysis of spectral absorption features in hyperspectral imagery. International Journal of Applied Earth Observation and Geoinformation, 5, 55-68.

Walter-Shea, E. A., Norman, J. M. (1991), Leaf optical properties. In Myneni, R. B., Ross, J. (Eds.), Photon-vegetation interactions. Springer Verlag Berlin Heidelberg New York, pp. 230-251.

Winter, M. E. (1999), N-FINDR: An algorithm for fast autonomous spectral end-member determination in hyperspectral data, Proc. SPIE Imaging Spectrometry, V, 266-275. 